\title{
Comparative Evaluation of Pyrethroid Insecticide Formulations against Triatoma infestans (Klug): Residual Efficacy on Four Substrates
}

\author{
Antonieta Rojas de Arias/ ${ }^{+}$, MJ Lehane*, CJ Schofield**, Alain Fournet ${ }^{* * *}$ \\ Departamento de Medicina Tropical, Instituto de Investigaciones en Ciencias de la Salud, Universidad Nacional de Asunción, \\ Rio de la Plata y Lagerenza, CP 2511, Asunción, Paraguay *School of Biological Sciences, University of Wales, Bangor, UK \\ **Department of Infectious and Tropical Diseases, London School of Hygiene and Tropical Medicine, London, UK \\ ***Institut de Recherche pour le Développement, Paris, France
}

We investigated the residual efficacy of four insecticide formulations used in Chagas disease vector control campaigns: cyfluthrin 12.5\% suspension concentrace (SC), lambda-cyhalothrin 10\% wettable powder (WP), deltamethrin $2.5 \%$ SC, and 2.5\% WP on four types of circular blocks of wood, straw with mud, straw with mud painted with lime, and mud containing 5\% of cement. Three concentrations of these insecticides were tested: the $L C_{90}$ (previously determined on filter paper), the double of the $L C_{90}$, and the recommended operational dose. For each bioassay test, 15 third-stage nymphs of Triatoma infestans (Klug) (Hemiptera: Reduviidae) were exposed for $120 \mathrm{~h}$ to each treatment at $24 \mathrm{~h}, 30,60,90$, and 180 days post-spraying. Mortality rates, moulting history and behaviour were recorded at 24, 48, 72, and 120 h of exposure. Mortality rates were highest during the first 30 days post-spraying. Highest mortality rates (above 50\%) were observed for deltamethrin $2.5 \%$ SC and lambda-cyhalothrin $10 \%$ WP on wood blocks up to three months post-spraying. Mud was the substrate on which treatments showed lowest persistence, with the other two substrates showing intermediate residual efficacy of all treatments. During the first 30 days WP formulations were not as effective as SC flowable formulations but, overall in the longer term, WP gave grater mortality rates of $\mathrm{T}$. infestans nymphs exposed at up to six months post-spraying. Porous surfaces, especially mud, showed most variability presumably due to absorption of the insecticide. In contrast the less porous surfaces (i.e. wood and lime-coated mud) kept mortality rates high for longer post-treatment, irrespective of the insecticide concentration used.

Key words: bioassays - efficacy - insecticides - pyrethroid - residuality - substrates - Triatoma infestans

Compounds from every class of insecticide have been tested against triatomine bugs (Hemiptera, Reduviidae), the vectors of Chagas disease in Latin America (Schofield 1985, Sequeda et al. 1986, Zerba 1999). Among the organochlorines, DDT showed relatively poor effect but gamma-HCH-BK was found to be very effective in early trials against Panstrongylus megistus Burmeister and Triatoma infestans (Klug) in Brazil and Argentina (Dias \& Pellegrino 1948, Romana \& Abalos 1948). Dieldrin was used with good results against Rhodnius prolixus (Stal) in Venezuela but mild resistance was observed in some areas (Sequeda et al. 1986). Various organophosphate and carbamate insecticides were also tested but they were more expensive and had no operational advantages over BHC (Schofield 1985). During the late 1970's and early 1980 's, trials of synthetic pyrethroids showed them to be more effective than BHC at lower doses (Pinchin et al.

Financial support: UNDP/World Bank/WHO Special Programme for Research and Training in Tropical Disease ${ }^{+}$Corresponding author. Fax: +2595-21-480.185. E-mail: arias1@telesurf.com.py

Received 26 February 2003

Accepted 28 August 2003
$1980,1981)$. Since the mid 1980's, several of the most common pyrethroids (deltamethrin, lambda-cyhalothrin, cyfluthrin, and cypermethrin) have become the main insecticides used operationally for control of Triatominae, because of their efficacy and persistence, as well as the minimal environmental pollution associated with their use (Pinchin et al. 1980, 1981, Schofield 1985).

Limiting factors for activity include the initial insecticide dose rate, nature of the sprayed surface as well as the age of insecticide deposits and the environmental conditions such as humidity and temperature (Nocerino 1981, Penna et al. 1984, Giga \& Canhao 1992, Fletcher \& Axtell 1993). The type of substrate, in terms of its porosity, is of particular importance. On porous surfaces such as mud, the insecticide deposit seems to lose activity much faster than on surfaces such as wooden boards, ceramics and tiles (Barlow \& Hadaway 1949, 1952, Penna et al. 1985). In the case of pyrethroids, chemical breakdown may also be expected on highly alkaline surfaces and on surfaces exposed to sunlight (Leahey 1985). In order to get a better knowledge of insecticide/ substrate interaction, we evaluated the residual efficacy of four commercial pyrethroid formulations currently used in bug control operations on four substrate materials commonly used for house construction in Paraguay. The experiments were performed in the Tropical Medicine Laboratory of the Instituto de Investigaciones en Ciencias de la Salud (IICS), Asunción, Paraguay. 


\section{MATERIALS AND METHODS}

Insects - T. infestans susceptible Paraguayan strain was maintained at the IICS. Groups of 30 bugs were kept in $18 \times 38$ $\mathrm{cm}$ jars at $28^{\circ} \mathrm{C}$ and $60-70 \%$ relative humidity and fed weekly on pigeons for $20 \mathrm{~min}$. Nymphs which had moulted to third stage $<1$ week previously were used for tests. After the period of exposure to insecticide, the insects were blood fed on a pigeon and observed for 15 days.

Substrate block - Four types of circular blocks $(9 \mathrm{~cm}$ diameter, $0.5 \mathrm{~cm}$ thick) were used as substrates to be treated with insecticide. The blocks were made of either wood, straw with mud, straw with mud painted with lime, or mud containing 5\% cement, all prepared at the Centro de Tecnología Apropiada (CTA), Universidad Católica Nuestra Señora de la Asunción, Paraguay. A total of 220 blocks were sprayed and held in cardboard boxes away from light and wind at laboratory conditions of temperature and humidity until used.

Wood blocks were made of "Petereby" Cordia trichotoma (Vell.), a typical wood used in rural areas of Paraguay to build windows, doors, and roof supports.

Soil-cement blocks were made of a hardened mixture of 5\% cement and soil components (sand, lime, and clay, proportions 50:20:30). The soil was pulverised mechanically and then sieved (sieve \# 4-4.8 mm). Portland cement was then added uniformly and mixed by hand to homogeneity with rainwater until a dense paste was obtained. Compacting was carried out in layers until a final thickness of $0.5 \mathrm{~cm}$ in moulds of $9 \mathrm{~cm}$ diameter was obtained. Resulting blocks were cured by coverage with plastic foil and occasional spraying with water for one week to avoid rapid drying.

Mud blocks were made from soil composed of 60:20:20 sand, lime, and clay. Straw or grass was added as a fibre to reduce cracks during the drying process. Compacting and curing were performed as with the soil cement blocks. To simulate the type of whitewash commonly used on walls, a mixture of lime (calcium oxide) and water $(500 \mathrm{mg} /$ $500 \mathrm{ml}$ ) was prepared and continuously stirred before application by brushing onto dried mud blocks. Two coats were applied with a 15 min-drying interval.

Insecticides - Four commercial products: cyfluthrin $12.5 \% \mathrm{SC}$, deltamethrin $2.5 \%$ suspension concentrate (SC), and $2.5 \%$ wettable powder (WP), and lambdacyhalothrin $10 \%$ WP were evaluated at three concentrations (Table I).

Concentration-response curves were first established by exposing $3 \mathrm{rd}$ stage nymphs of $T$. infestans $(\mathrm{n}=15 /$ test $\mathrm{x} 2$ replicates) for $24 \mathrm{~h}$ to insecticide residues on disks of filter paper (Whatman nr 1). Six dilutions of each insecticide were prepared: concentrations of active ingredient (a.i. expressed in $\mathrm{mg} / \mathrm{m}^{2}$ ) were $6,12.5,25,50$, 100 , and $200 \mathrm{mg}$ ai $/ \mathrm{m}^{2}$. Each insecticide was first mixed in water following the manufacturer instructions, with vigorous shaking to ensure an even suspension and serial dilutions were prepared quickly to prevent sedimentation. Each filter paper disk placed on an inverted $9 \mathrm{~cm}$ diameter Petri dish was treated with $1.2 \mathrm{ml}$ of freshly shaken insecticide suspension of sufficient volume to wet the filter paper with no run-off. Duplicate experiments to determine concentration-response curves were run two weeks apart. Log probit analysis used the Toxicologie TM Programme (G Febvay \& Y Rahbe, Insa-Inra 406, F-69621 Villeurbanne cedex, France) to calculate the $\mathrm{LC}_{50}$ and $\mathrm{LC}_{90}$.

Bioassays of treated substrates - The four types of blocks were then sprayed with each pyrethroid formulation at three concentrations: the recommended commercial dose, the $\mathrm{LC}_{90}$, and $2 \times$ the $\mathrm{LC}_{90}$. To do this, the blocks were put on an horizontal paper surface forming an area of $0.22 \mathrm{~m}^{2}$ to be sprayed with a $10-15 \mathrm{~cm}$ swath from a 500 $\mathrm{ml}$ plastic sprayer with the nozzle held $45 \mathrm{~cm}$ from the block.

The amount of insecticide required to cover the area of $0.22 \mathrm{~m}^{2}$ at the target rate was diluted in $50 \mathrm{ml}$ of distilled water for application. Pre-weighed filter papers were also treated by the same procedure, dried (with a hair dryer) and re-weighed immediately to give a further estimate of the amount of insecticide applied to the surface. Applied concentrations were confirmed by HPLC residue analysis by Roussel Uclaf (later Aventis, now Bayer) Berkhamsted, UK.

Efficacy of insecticide treated substrates was bioassayed with unfed 3rd stage nymphs of $T$. infestans exposed to three concentrations of treatment on each of the four substrates. The insects were held in place using WHO (1995) bioassay cones (9 $\mathrm{cm}$ diameter designed for mosquito bioassays on walls) nailed to the treated blocks. The nymphs ( $\mathrm{n}=15$ per test $\mathrm{x} 2$ replicates) were held on untreated (control) and treated surfaces for $120 \mathrm{~h}$.

Mortality rates, moulting history and behaviour were recorded after 24, 48, 72, and $120 \mathrm{~h}$ exposure at $24 \mathrm{~h}, 30,60$, 90 , and 180 days post-spraying. Surviving insects were transferred onto clean filter papers and held at $28^{\circ} \mathrm{C}$ and $60-70 \%$ relative humidity for 15 days to check further mortality.

An insect was considered dead if no locomotory activity could be seen when it was prodded. Moribund insects were considered dead at the time of reading if they did not show any subsequent recovery of activity during the following 15 days.

Mortality data (mean of two independent tests) were analyzed using the statistical package MINITAB. A chi square contingency analysis was performed to investigate the relationship between insect mortality and persistence of deposits at different post-spray times for each substrate. Chi square analysis of the contingency tables was also performed to establish significant differences in mortality rates between different insecticide concentrations on the various substrate types. The most effective concentration per block was determined by subdividing contingency tables and pooling the different concentrations in order to analyse variations in chi square with changes in degrees of freedom.

\section{RESULTS}

The initial $\mathrm{LC}_{50}$ value (determined from treated filter paper test) closely approximates the commercially recommended operational application rate of each insecticide tested (Table I). Therefore, further tests evaluated these operational application rates as well as the $\mathrm{LC}_{90}$ and the double of the $\mathrm{LC}_{90}$ (for $24 \mathrm{~h}$ exposure on 
TABLE I

Technical information on insecticides applied

\begin{tabular}{|c|c|c|c|c|c|c|}
\hline \multirow[b]{2}{*}{ Compound } & \multirow{2}{*}{$\begin{array}{l}\text { Trade } \\
\text { name }\end{array}$} & \multirow[b]{2}{*}{ Formulation } & \multirow{2}{*}{$\begin{array}{l}\text { Recommended } \\
\text { application } \\
\text { rate }\end{array}$} & \multicolumn{2}{|c|}{ Concentration-response-curve $\left(\mathrm{mg}\right.$ a. $\left.\mathrm{i} / \mathrm{m}^{2}\right)$} & \multirow[b]{2}{*}{ Manufacturer } \\
\hline & & & & $\mathrm{LC}_{50}$ & $\mathrm{LC}_{90}$ & \\
\hline Lambda-cyhalothrin & ICON & $10 \% \mathrm{WP}$ & $30 \mathrm{mg} / \mathrm{m}^{2}$ & $32.7(24.6-43.4)$ & $62.5(59.5-114.5)$ & $\begin{array}{l}\text { Zeneca (now } \\
\text { Singenta), UK }\end{array}$ \\
\hline Deltamethrin & K-Othrine & $2.5 \% \mathrm{SC}$ & $25 \mathrm{mg} / \mathrm{m}^{2}$ & $31.1 / 20.5-47.2)$ & $187.8(106.6-330.7)$ & $\begin{array}{l}\text { Aventis (now } \\
\text { Bayer) Germany }\end{array}$ \\
\hline Deltamethrin & K-Othrine & $2.5 \% \mathrm{WP}$ & $25 \mathrm{mg} / \mathrm{m}^{2}$ & $38.4-4-54.4)$ & $164.4(105.4-246.6)$ & $\begin{array}{l}\text { Aventis (now } \\
\text { Bayer)Germany }\end{array}$ \\
\hline Cyfluthrin & Responsar & $12.5 \% \mathrm{SC}$ & $25 \mathrm{mg} / \mathrm{m}^{2}$ & $32.2(23.1-36.4)$ & $182.4(110.2-241.1)$ & $\begin{array}{l}\text { Bayer, AG, } \\
\text { Germany }\end{array}$ \\
\hline
\end{tabular}

WP: wettable powder; SC: flowable suspension concentrate

filter paper) to evaluate the residual efficacy of insecticides on different treated substrates blocks.

High mortality rates (50-100\%) were observed on three of the four substrates (i.e. wood blocks, lime-coated mud, and soil cement blocks) during the first three months of post-treatment with cyfluthrin $12.5 \% \mathrm{SC}$ at $25 \mathrm{mg}$ ai $/ \mathrm{m}^{2}$, deltamethrin $2.5 \% \mathrm{SC}$ at $25 \mathrm{mg}$ ai $/ \mathrm{m}^{2}$ or lambdacyhalothrin $10 \% \mathrm{WP}$ at $30 \mathrm{mg}$ ai $/ \mathrm{m}^{2}$. The activity of deltamethrin $2.5 \%$ WP at $25 \mathrm{mg}$ ai $/ \mathrm{m}^{2}$ decayed drastically after one month and, as post-spraying time increased, longer exposure periods were required for all four products to achieve peak mortality rates. Also, for all four insecticides at each dosage, longer exposure was required on treated mud than on the other three substrates to achieve the same mortality (data not shown). Nevertheless, 100\% mortality was observed when bugs were exposed on mud blocks freshly treated with deltamethrin SC or lambda-cyhalothrin WP for $72 \mathrm{~h}$ (data not shown). Control mortality on all types of untreated substrate was usually zero and never surpassed $7 \%$ (2/30). Therefore no correction was made for control mortality in data analysis.

One month post-spraying the wood, lime-coated mud and soil-cement blocks still showed good efficacy against nymphs exposed for 24-48 h but at 3-6 months postspraying, 72-120 h of exposure were required to achieve maximum mortality. Insecticide activity was still present six months post-spraying of all four products, at least on wood and soil-cement substrates, provided the exposure time was sufficient (data not shown). Nine months postspraying, a low mortality rate ( $20 \%$ or less) was only observed in substrates sprayed with wettable powders except on wood blocks sprayed with deltamethrin WP where mortality was zero.

Table II compares mortality of bugs exposed by $24 \mathrm{~h}$ on blocks with $30,60,90$, and 180 days post-spraying. The decline of insecticide activity with time on each substrate was clearly demonstrated for all four products. On wood and soil-cement blocks with each treatment, mortality rates of $T$. infestans nymphs were significantly higher $(\mathrm{p}<0.001)$ at $1-3$ months than at 6 months postspraying. On lime-coated mud blocks, the two WP formulations were initially less effective than the two flowable formulations but performance of lambdacyhalothrin WP was similar to that of the SCs over 3-6 months. Deltamethrin SC gave higher initial mortalities on all surfaces, with persistence similar to that of lambdacyhalothrin WP. Cyfluthrin SC performed better on wood and lime-coated mud blocks but very poorly on uncoated mud blocks and on soil blocks. For all products, wood and lime-coated mud blocks were better surfaces than uncoated mud or soil-cement blocks.

Table III shows chi-square contingency table analysis applied to determine the most effective insecticide at 6 months after spraying (excluding cyfluthrin SC which had entirely lost residual efficacy). The highest mortalities were pooled and compared over all concentrations; if no statistical significance was observed between different degrees of freedom, new pools were performed until significant differences were found. No simple pattern emerges from these data except that the persistence of each treatment clearly depends upon the substrate. It is interesting to note, though difficult to explain, that the highest dose of the products did not produce the longest persistence. Deltamethrin 2.5\% WP was the most residual insecticide on all substrates when applied at the highest dose tested (i.e. $\mathrm{LC}_{90} \times 2$ ). At doses more likely to be used in field (i.e. recommended rate and $\mathrm{LC}_{90}$ ), the flowable formulation of deltamethrin SC showed best effects overall, especially on lime-coated mud blocks.

\section{DISCUSSION}

Many previous studies (Burkholder \& Dicke 1966, Jain \& Yavav 1989, Fletcher \& Axtell 1993) indicated that the insecticide formulation, the insect stage, as well as the insecticide exposure method are critical in insecticide evaluation. This study was designed to compare residual efficacy of two formulations of four pyrethroids against nymphs of triatomine bugs on substrates representing those commonly used in domestic habits of rural South America. Products chosen were considered to be those most likely to be of benefit in campaigns of house spraying to control vectors of Chagas disease. Insecticide trials against triatomines, including treatments on different types of surfaces, have been previously reported by Penna et al. (1985), Schofield and Williams (1985), Oliveira Filho (1992, 1999), Diotaiuti and Texeira Pinto (1991), Guillén et al. (1997), Rojas de Arias et al. (1999), and Rojas de Arias and Fournet (2002). 
TABLE II

Triatoma infestans mortality rates following $24 \mathrm{~h}$ exposure to four substrates treated with four products tested one, three, six months post-treatment

\begin{tabular}{|c|c|c|c|c|c|}
\hline \multirow[b]{3}{*}{ Insecticide } & \multicolumn{3}{|c|}{ Dead triatomines/total(percent) } & \multicolumn{2}{|c|}{ Chi-square values (DF:1) ${ }^{a} ; \mathrm{p}$ values } \\
\hline & \multicolumn{3}{|c|}{ Post-treatment days } & \multirow{2}{*}{$\begin{array}{c}30 \text { vs } \\
(90+180) \text { days }\end{array}$} & \multirow{2}{*}{$\begin{array}{c}(30+90) \mathrm{vs} \\
180 \text { days }\end{array}$} \\
\hline & 30 & 90 & 180 & & \\
\hline \multicolumn{6}{|c|}{ Wood blocks } \\
\hline Deltamethirn $2.5 \% \mathrm{SC}$ & $30 / 30(100)$ & $30 / 30(100)$ & $6 / 30(20)$ & $14.38 ;<0.001$ & $61.43 ;<0.001$ \\
\hline Deltamethrin $2.5 \% \mathrm{WP}$ & $23 / 30(76.7)$ & $2 / 30(7)$ & $2 / 30(7)$ & $43.39 ;<0.001$ & $10.06 ;<0.001$ \\
\hline Lambda-cyhalothrin 10\% WP & $30 / 30(100)$ & $18 / 30(60)$ & $8 / 30(27)$ & $24.96 ;<0.001$ & $21.99 ;<0.001$ \\
\hline Cyfluthrin $12.5 \% \mathrm{SC}$ & $23 / 30(76.7)$ & $18 / 30(60)$ & $30 / 30(100)$ & $0.01 ; 0.93$ & $10.28 ;<0.01$ \\
\hline Control & $2 / 30(7)$ & $0 / 30(0)$ & $0 / 30(0)$ & & \\
\hline \multicolumn{6}{|c|}{ Mud blocks } \\
\hline Deltamethirn $2.5 \% \mathrm{SC}$ & $17 / 30(56.7)$ & $0 / 30(0)$ & $0 / 30(0)$ & $38.30 ;<0.001$ & $8.71 ;<0.01$ \\
\hline Deltamethrin $2.5 \% \mathrm{WP}$ & $13 / 30(43.3)$ & $0 / 30(0)$ & $2 / 30(7)$ & $20.25 ;<0.001$ & $2.91 ;<0.05$ \\
\hline Lambda-cyhalothrin 10\% WP & $17 / 30(56.7)$ & $6 / 30(20)$ & $4 / 30(13)$ & $13.39 ;<0.001$ & $4.82 ;<0.01$ \\
\hline Cyfluthrin $12.5 \% \mathrm{SC}$ & $0 / 30(0)$ & $6 / 30(20)$ & $0 / 30(0)$ & - & - \\
\hline Control & $2 / 30(7)$ & $0 / 30(0)$ & $0 / 30(0)$ & & \\
\hline \multicolumn{6}{|c|}{ Lime-coated mud blocks } \\
\hline Deltamethirn $2.5 \% \mathrm{SC}$ & $30 / 30(100)$ & $10 / 30(33)$ & $16 / 30(53)$ & $24.96 ;<0.001$ & $1.0 ; 0.31$ \\
\hline Deltamethrin $2.5 \%$ WP & $15 / 30(50)$ & $8 / 30(27)$ & $2 / 30(7)$ & $9.48 ;<0.01$ & $8.48 ;<0.01$ \\
\hline Lambda-cyhalothrin $10 \% \mathrm{WP}$ & $16 / 30(53.3)$ & $10 / 30(33)$ & $14 / 30(46)$ & $0.95 ; 0.33$ & $0.01 ; 0.94$ \\
\hline Cyfluthrin $12.5 \% \mathrm{SC}$ & $21 / 30(70)$ & $4 / 30(25)$ & $0 / 30(0)$ & $39.85 ;<0.001$ & $15.25 ;<0.001$ \\
\hline Control & $2 / 30(7)$ & $7 / 30(7)$ & $0 / 30(0)$ & & \\
\hline \multicolumn{6}{|c|}{ Soil-cement blocks } \\
\hline Deltamethirn $2.5 \% \mathrm{SC}$ & $30 / 30(100)$ & $2 / 30(7)$ & $0 / 30(0)$ & $81.56 ;<0.001$ & $24.55 ;<0.001$ \\
\hline Deltamethrin $2.5 \% \mathrm{WP}$ & $25 / 30(83.3)$ & $8 / 30(27)$ & $4 / 30(13)$ & $30.57 ;<0.001$ & $12.69 ;<0.001$ \\
\hline Lambda-cyhalothrin $10 \% \mathrm{WP}$ & $10 / 30(33.3)$ & $0 / 30(0)$ & $0 / 30(0)$ & $19.25 ;<0.001$ & $4.06 ;<0.01$ \\
\hline Cyfluthrin $12.5 \% \mathrm{SC}$ & $6 / 30(20)$ & $4 / 30(13)$ & $0 / 30(0)$ & $2.38 ; 0.06$ & $4.06 ;<0.01$ \\
\hline Control & $2 / 30(7)$ & $0 / 30(0)$ & $0 / 30(0)$ & & \\
\hline
\end{tabular}

$a$ : Chi-square. Fifteen nymphs $(2 \times 15 /$ test $)$ were exposed for $24 \mathrm{~h}$ on each substrate sprayed with insecticide at commercial dose and mortality was scored after 15 days recovery period.

We defined similar values to those found by Schofield and Williams (1985) when deltamethrin concentrationresponse was evaluated using a residual exposure method to test different insecticides against triatomines. For instance, $\mathrm{LC}_{50}$ at $24 \mathrm{~h}$ in second stage nymphs of $T$. infestans nymphs reached at $32 \mathrm{mg} / \mathrm{m}^{2}$ while $136 \mathrm{mg} / \mathrm{m}^{2}$ is mentioned as $\mathrm{LC}_{90}$. Using technical grade deltamethrin and following $24 \mathrm{~h}$ exposure, Zerba et al. (1988), reported $\mathrm{a} \mathrm{LC}_{50}$ of $0.03 \mu \mathrm{g} / \mathrm{cm}^{2}$ for fifth instar-nymphs. Therefore, concentration-response data using filter paper as standard procedure provided important baseline information under laboratory conditions and could be a useful tool in evaluating differences in insecticide susceptibility in further studies.

The interaction between insecticide and substrate surface resulted in a rapid decrease of its activity (data not shown). The nature of the substrate plays an important role in the rate at which this decay occurs. In these trials, insecticide was most persistent on wood and lime-coated mud surfaces. These surfaces are less porous in nature avoiding the quick penetration of the insecticide occurring on mud blocks (Williams et al. 1982, 1983, Giga \& Canhao 1992).

The most rapid loss in insecticide toxicity occurs on mud blocks indicating strong absorption or breakdown of the insecticide by alkaline substances (White 1982,
Diotaiuti \& Texeira Pinto 1991). The lack of insecticide persistence on porous surfaces has been noted before (Barlow \& Hadaway 1949, 1952, Williams et al. 1982, 1983, Jain \& Yarav 1989, Giga \& Canhao 1992). Moreover, the notable variability in mortality on porous substrates, such as those reported here, have also been noted by other authors (Diotaiuti \& Texeira Pinto 1991).

Concrete surfaces are also porous substrates and, for example, the application of corn dust to them causes a decline in the $\mathrm{pH}$ and a reduction in its porosity, improving the residual effect of insecticides (White 1982). While testing commercial sealants, Arthur (1994) found that applying sealants to concrete prior to insecticide application formed a waterproof barrier and improved residual efficacy of cyfluthrin WP. As reported here, limecoated mud blocks showed improved insecticide efficiency. This may be due to various reasons but most probably because of improved particle adhesion and decreased porosity of the mud. Lime is obtained by the application of heat to calcium carbonate that produces carbonic anhydride (gas) and calcium oxide (quick lime). Slow hardening in normal conditions is one of the main characteristics of lime reacting with atmospheric carbon dioxide which begins at $24 \mathrm{~h}$ of kneading the paste and is completed at 6 months forming neutral calcium carbonate which is finally insoluble (CTA 1992). This property and 
TABLE III

Insecticide bioassays results for persistence analysis at six months post-spraying according to the applied concentration

\begin{tabular}{|c|c|c|c|c|c|c|c|c|c|}
\hline \multirow[b]{3}{*}{ Insect status } & \multicolumn{3}{|c|}{ Deltamethrin $2.5 \% \mathrm{SC}$} & \multicolumn{3}{|c|}{ Deltamethrin $2.5 \% \mathrm{WP}$} & \multicolumn{3}{|c|}{ Lambdacyhalothrin 10\% WP } \\
\hline & \multicolumn{3}{|c|}{ Concentration $\left(\mathrm{mg}\right.$ a.i. $\left./ \mathrm{m}^{2}\right)$} & \multicolumn{3}{|c|}{ Concentration (mg a.i. $\left./ \mathrm{m}^{2}\right)$} & \multicolumn{3}{|c|}{ Concentration (mg a.i. $/ \mathrm{m}^{2}$ ) } \\
\hline & OD25 & $\mathrm{LC}_{90} 188$ & $2 \times \mathrm{LC}_{90} 376$ & OD25 & $\mathrm{LC}_{90} 164$ & $2 \times \mathrm{LC}_{90} 329$ & OD30 & $\mathrm{LC}_{90} 62$ & $2 \times \mathrm{LC}_{90} 125$ \\
\hline \multicolumn{10}{|c|}{ Wood blocks } \\
\hline Dead & 3 & $14^{a, b}$ & $14^{a, b}$ & 1 & 2 & $14^{a, b}$ & 4 & 2 & $10^{b}$ \\
\hline Alive & 12 & 1 & 1 & 14 & 13 & 1 & 11 & 13 & 5 \\
\hline \multicolumn{10}{|c|}{ Mud blocks } \\
\hline Dead & 0 & 1 & 2 & 1 & 0 & $4^{a}$ & 2 & 2 & $11^{a}$ \\
\hline Alive & 15 & 14 & 13 & 14 & 15 & 11 & 13 & 13 & 4 \\
\hline \multicolumn{10}{|c|}{ Lime-coated mud blocks } \\
\hline Dead & $8^{b, c}$ & $11^{a, b, c}$ & $7^{c}$ & 1 & 5 & $14^{a, b, c}$ & $7^{\mathrm{c}}$ & 1 & $10^{a, b, c}$ \\
\hline Alive & 7 & 4 & 8 & 14 & 10 & 1 & 8 & 14 & 5 \\
\hline \multicolumn{10}{|c|}{ Soil cement blocks } \\
\hline Dead & 0 & $9^{a}$ & 1 & 2 & 0 & $14^{a}$ & 0 & 1 & 4 \\
\hline Alive & 15 & 6 & 14 & 13 & 15 & 1 & 15 & 14 & 11 \\
\hline
\end{tabular}

OD: operational dose; Wood blocks: Chi-square $=71.362 \mathrm{df}=8 \mathrm{p}<0.001 ; a$ : first pooling $=71.362 \mathrm{df}=6 \mathrm{p}<0.001 ;$ difference $=71.362-71.362=0 ; b$ : second pooling $=68.154 \mathrm{df}=5 \mathrm{p}<0.001 ;$ pooling effect $=71.312-68.154=3.2080 .10>\mathrm{p}>0.05 ;$ Mud blocks: Chi-square $=43.498 \mathrm{df}=8 \mathrm{p}<0.001 ; a$ : first pooling $=31.942 \mathrm{df}=6 \mathrm{p}<0.001$; pooling effect $=43.498-31.942=11.556$ $\mathrm{df}=7 \mathrm{p}<0.001$; Lime-coated mud blocks: Chi-square $=40.346 \mathrm{df}=8 \mathrm{p}<0.001 ; a$ : first pooling $=38.028 \mathrm{df}=6 \mathrm{p}<0.001$; difference: $2.318 \mathrm{df}=20.50>\mathrm{p}>0.25$ (not significant), $b$ : second pooling $=35.332 \mathrm{df}=5 \mathrm{p}<0.001$; difference $=2.696 \mathrm{df}=$ $10.25>\mathrm{p}>0.10$ (not significant), $c$ : third pooling $=35.332 \mathrm{df}=5 \mathrm{p}<0.001$; pooling effect $=35.332-30.319=5.013 \mathrm{df}=20.10$ $>\mathrm{p}>0.05$; Soil cement blocks: Chi-square $=72.441 \mathrm{df}=8 \mathrm{p}<0.001 ; a$ : pooling $=12.178 \mathrm{df}=70.10>\mathrm{p}>0.05$; pooling effect $=72.441-12.178=60.263 \mathrm{df}=1 \mathrm{p}<0.001$

This table shows the best concentration per block sub-dividing contingency tables and pooling the different concentrations. Variations in chi-square with changes in degrees of freedom were calculated per each block. The three concentrations of each product correspond to commercial doses, $\mathrm{LC}_{90}$ and $2 \times \mathrm{LC}_{90}$.

the decline in the $\mathrm{pH}$ value on the surface would avoid the breakdown of the applied insecticide. Further studies should be done to determine the period of time required to neutralize the effect of lime on insecticides and to maximize their sealant properties.

Our data have shown that the flowable formulation (deltamethrin SC 25) killed a high percentage of insects at an early age of insecticide deposits (up to 30 days). Nevertheless, wettable powder on lime-coated blocks such as lambda-cyhalothrin WP10 killed less insects in the short term but the effect was expanded up to 9 months, showing a similar performance for both formulations (Table II).

Independence of triatomine mortality and insecticide concentration was observed for flowable formulations but not in all wettable powders (Table III). Wettable formulations are often more effective at controlling insects than emulsions on porous surfaces (Schofield \& Pinchin 1979, Willians et al. 1982). In WP, active ingredients tend to filter out the liquid and remain on the surface of the porous materials rather than penetrating deeply into the substrate being readily available to contact insects (Williams et al. 1982). Overall, the dependence of mortality and concentration begins to disappear with the age of the spray deposit.

In field studies, initial sprayings with pyrethroids have eliminated domestic bug populations for several years at low dose and cost (Gurtler et al. 1994, Rojas de Arias et al.
1999). Studies carried out in laboratory conditions have confirmed these results (Diotaiutti \& Teixeira Pinto 1991, Ferro et al. 1995) indicating that pyrethroids persistence depends on the product and type of substrate. However, it should be remarked that the good performance of pyrethroids does not entirely depend on the residual effect of the insecticide as residual effect relies on the amount of insecticide remaining on the treated surface while reinfestation is a consequence of many different factors mainly related to the initial impact on the insect colony and the surface type. Effectiveness of pyrethoids in their initial impact is more relevant than the residual effect that promptly decreases on all types of surfaces. The results of this laboratory study showed a very low residual effect of the pyrethroids on all substrate types used beyond 90 days post-spraying with the only exception of deltamethrin SC 25 on wood blocks but it is important to note that lime-coated surfaces sprayed with flowable or wettable formulations have shown a residual activity beyond 90 days, time enough to eliminate any nymph that hatches from eggs after the initial clean-out.

\section{ACKNOWLEDGMENTS}

To manufacturers Aventis (formerly Rousell Uclaf, now Bayer), Bayer AG, and Zeneca (now Singenta) for kindly supplying samples of the insecticides tested. To the technical staff of the Departament of Tropical Medicine for their help and assistance in the preparation of the experiments. 


\section{REFERENCES}

Arthur FH 1979. Residual efficacy of cyfluthrin emulsifiable concentrate and wettable powder formulations on porous concrete and on concrete sealed with commercial products prior to insecticide application. Stored Prod Res 30: 79-86.

Barlow F, Hadaway AB 1949. Further studies on loss of insecticides by absorption into mud and vegetation. Bul Entomol Res 40: 323-343.

Barlow F, Hadaway AB 1952. Some factors affecting the availability of contact insecticides. Bull Entomol Res 43: 91-100.

Burkholder WE, Dicke RJ 1966. The toxicity of malathion and fenthion to dermestid larvae as influenced by various surfaces. J Economic Entomol 59: 253254.

CTA-Centro de Tecnología Apropiada 1992. Uso de la Tierray Materiales Alternativos en la Construcción, Centro de Publicaciones, Universidad Católica, Asunción, Paraguay, $372 \mathrm{pp}$

Dias E, Pellegrino J 1948. Alguns ensaios com "gammexanne" no combate aos transmisores da doença de Chagas. Brasil Médico 68: 85-191.

Diotaiuti L, Texeira Pinto C 1991. Susceptibilidade biológica do Triatoma sordida e Triatoma infestans a deltametrina e lambdacyhalotrina em condições de campo. Rev Soc Bras Med Trop 24: 151-155.

Ferro E, Rojas de Arias A, Ferreira ME, Simancas LC, Rios LS, Rosner JM 1995. Residual effect of lambdacyhalothrin on Triatoma infestans. Mem Inst Oswaldo Cruz 40: 415-419.

Fletcher MG, Axtell RC 1993. Susceptibility of the bedbug, Cimex lectularius, to selected insecticides and various surfaces. Med \& Vet Entomol 7: 69-72.

Giga DP, Canhao SJ 1992. Persistence of insecticide spray deposits on different surfaces against Prostephanus truncatus (Horn) and Sitophilus Zeamais (Motsch.). Insect Sc Appl 13: 755-762.

Guillén G, Diaz R, Jemio A, Cassab A, Texeira Pintos C, Schofield CJ 1997. Chagas disease vector control in Tupiza, Sourthern Bolivia. Mem Inst Oswaldo Cruz 92: 1-8.

Gurtler RE, Petersen RM, Cecere MC, Schweigmann NJ, Chuit R, Gualtieri JM, Wisnivesky Colli C 1994. Chagas disease in Northwest Argentina: risk of domestic re-infestation by Triatoma infestans after a single community wide application of deltamethrin. Trans R Soc Trop Med Hyg 88: 27-30.

Jain S, Yadav TD 1989. Persistence of deltamethrin, etrimfos, and malathion on different storage surfaces. Pesticides 23: 21-24.

Leahey JP 1985. The Pyrethroid Insecticides, Taylor \& Francis, London, $180 \mathrm{pp}$.

Nocerino F 1981. Afloramiento de cristales de insecticidas con el humedecimiento en las superficies rociadas. Bol Direc Malariol Saneam Amb 21: 54-58.

Oliveira Filho AM 1984. New alternatives for Chagas disease control. Mem Inst Oswaldo Cruz 79 (Suppl.): 117-123.

Oliveira Filho AM 1992. Testing lambdacyhalothrin against the main vectors of Chagas disease in Latin America. Unpublished report for I.C.I. Universidade Federal do Rio de Janeiro, Rio de Janeiro, Brazil, 51 pp.

Oliveira Filho AM 1999. Differences of susceptibility of five triatomine species to pyrethroid insecticides. Implications for Chagas disease vector control. Mem Inst Oswaldo Cruz 94 (Suppl.): 425-428.
Penna R, Bosworth A, Brasil IA, Marsden PD 1984. Persistência da atividade residual do BHC na superfície de diferentes materiais de construção. Rev Soc Bra Med Trop 17: 95-99.

Penna R, Oliveira AEX, Ferreira MFN, Jonhnson C, Bosworth A, Marsden PD 1985. The influence of building materials on the residual action of BHC. Mem Inst Oswaldo Cruz 80: 443-445.

Pinchin R, Oliveira Filho AM, Fanara DM, Gilbert D 1980. Ensaio de campo para avaliação das probabilidades de uso da decametrina (OMS 1948) no combate a triatomíneos. Rev Bras Malariol Doen Trop 32: 36-41.

Pinchin R,Oliveira Filho AM, Gilbert B 1981. Field trial of permethrin for the control of Triatoma infestans. Bull PAHO 15: 370-376.

Rojas de Arias A, Fournet A 2002. Fipronil insecticide: novel application against triatomine insect vectors of Chagas disease. Mem Inst Oswaldo Cruz 97: 535-539.

Rojas de Arias A, Ferro E, Ferreira ME, Simancas L 1999. Chagas disease vector control through different interventions modalities in endemic localities of Paraguay. Bull WHO 77: 331-339.

Romana C, Abalos JM 1948. Accion del "gammexane" sobre los triatomideos. "Control" domiciliario. An Inst Med Reg Tucuman 2: 95-106.

Schofield CJ 1985. Control of Chagas disease vectors. Br Med Bull 41: 187-194.

Schofield CJ, Pinchin R 1979. The design of insecticides for the control of vectors of Chagas disease. II Congreso International sobre a doenca de Chagas, Rio de Janeiro, Brazil (abstract)

Schofield CJ, Williams NG 1985. Baseline data for determing the resistence or suceptibility of triatomine bugs to insecticides. London School of Tropical Medicine. Unpublished report to the World Health Organization, $104 \mathrm{pp}$.

Sequeda MG, Villalobos L, Maekelt GA, Acquatella H, Velasco J, Gonzalez JR, Anselmi G 1986. Enfermedad de Chagas. VII Congreso Venezolano de Salud Publica, Vol. II, p. 907-1029.

White NDG 1982. Effectiveness of malathion and pirimiphos methyl applied to plywood and concrete to control Prostephanus truncatus (Coleoptera: Bostrichidae). Proc Entomol Soc Ont 113: 65-69.

WHO 1995. Supplies for monitoring insecticide resistance in disease vectors. Document. World Health Organization/ MAC/95.1073 and WHO/CTD/vec/95.998, Geneva, 14 pp.

Williams P, Semple RL, Amos TG 1982. Relative toxicity and persistence of one carbamate and three organophosphate insecticide on concrete, wood and iron surfaces for control of grain insects. J Appl Entomol 14: 35-40.

Williams P, Semple RL, Amos TG 1983. Relative toxicity and persistence of three pyrethroid insecticide on concrete, wood and iron surfaces fro control of grain insects. $J$ App Entomol 15: 7-10.

Zerba EN 1999. Past and present of Chagas vector control and future needs. Document WHO/CDS/WHOPES/GCDPP/ 99.1. WHO, Geneva, 25 pp.

Zerba EN, Licastro SA, Wood EJ, Picollo de Villar MI 1988. Insecticides: mechanism of action. In RR Brener, AM Stoka (eds), Chagas Disease Vectors Vol. III, Biochemical Aspects and Control, CRC Press, Florida, US, p. 101-120. 